\title{
El sistema normativo aduanero del Perí
}

\section{The Customs Regulatory System in Peru}

Marco Antonio Huamán Sialer*

http://dx.doi.org/10.21503/lex.v13i16.858

* Abogado por la Universidad Nacional de Trujillo. Postdoctor con Mención e Producción Científica. PhD con Mención en Estudios Legales Internacionales por la Atlantic International University Estados Unidos de Norteamérica. Doctor en Derecho y Master en Aduanas por la UAP. Especialista de Aduanas por la Escuela Nacional de Aduanas hoy IAT/SUNAT. Posgrado en Tributación por la Universidad de Lima. Curso de Posgrado sobre Nuevas Técnicas Aduaneras Internacionales en la Unión Europea por el Instituto de Estudios Fiscales. Madrid. España. Pasantía en la Universidad de Brasilia. Brasil. Estudios concluidos de Doctorado en Educación por la Universidad Nacional Mayor de San Marcos. Estudios concluidos de Maestría en Derecho con Mención en Derecho Internacional Económico por la Pontificia Universidad Católica del Perú. Docente a nivel de Posgrado en la Universidad Nacional Mayor de San Marcos, Pontificia Universidad Católica del Perú, Universidad de Lima, Universidad Federico Villarreal, Universidad Nacional de Ingeniería, UAP y en la Universidad ESAN. Vocal Presidente de la Sala de Aduanas del Tribunal Fiscal. E-mail:m_huaman@doc.uap.edu.pe

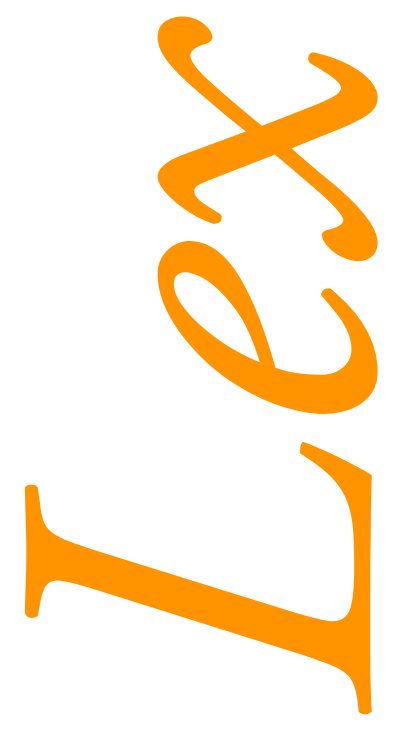




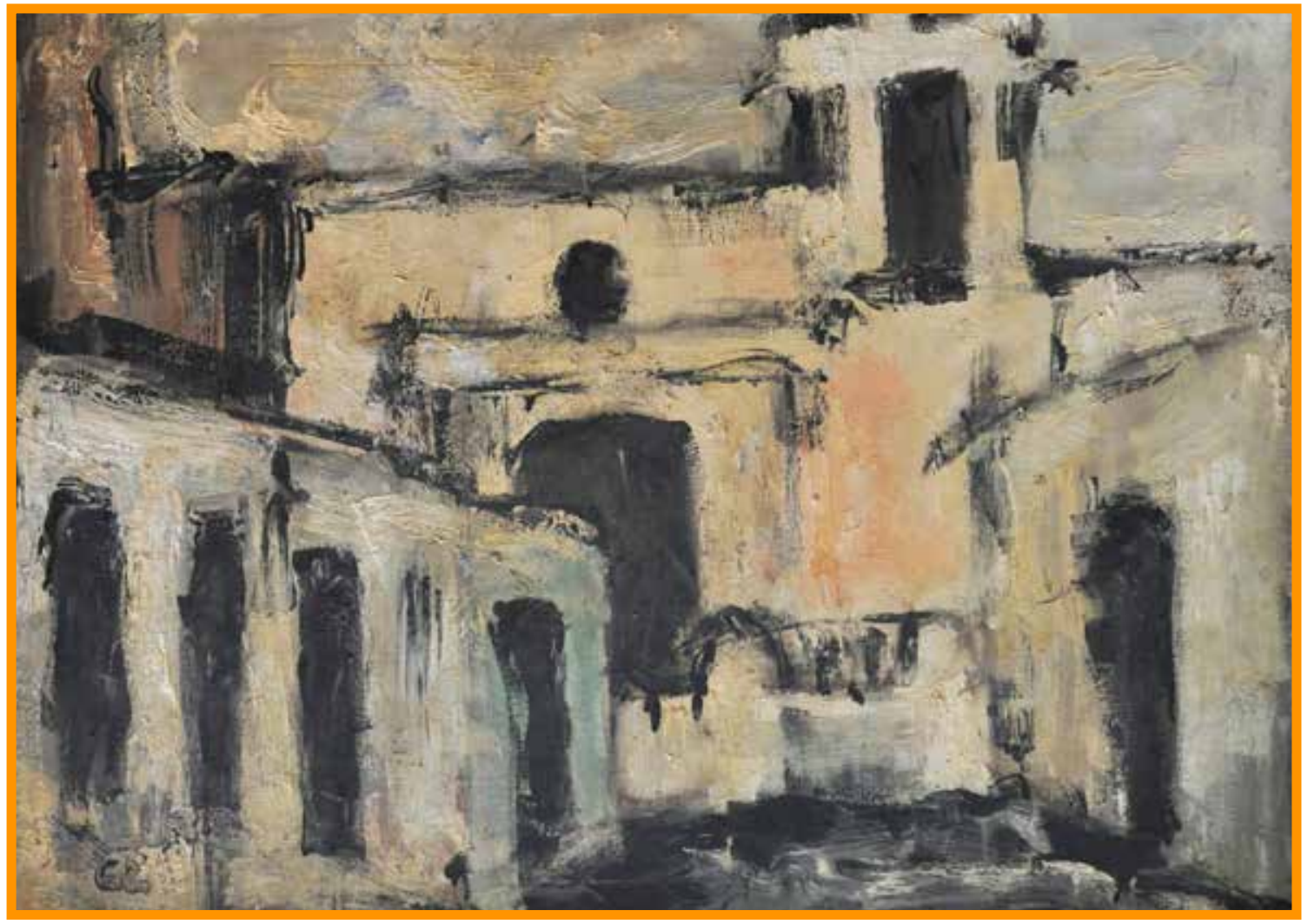

Virgen de las cabezas. Primer premio Lloyd aéreo Boliviano, año 1 962. Elke McDonald 


\section{RESUMEN}

En el presente trabajo se definen en primer lugar las categorías esenciales que nos permiten definir claramente el sistema aduanero vigente en nuestro país, al mismo tiempo que nos muestra en un didáctico resumen la estructura sobre la que se asienta su funcionamiento. Adicionalmente se hace mención tanto de la legislación interna como internacional que permiten regular el tráfico de mercancías y regular la actividad y operatividad aduanera.

Palabras clave: sistema aduanero, comercio exterior, actividad aduanera, tráfico internacional.

\section{ABSTRACT}

In this paper, we first defined the essential categories that allow us to clearly define the existing customs system in our country, while showing us a summary didactic structure on which its operation is based. Additionally, it mentions both domestic and international law that can regulate the traffic of goods and the customs activity and operability.

Key words: customs system, foreign trade, customs activities, international traffic. 

Dara definir el Sistema Aduanero del Perú primero debo precisar que se entiende por 1 sistema y como tal se define como un conjunto de reglas y principios sobre una materia racionalmente enlazados entre sí. Asimismo es un conjunto de cosas que relacionadas entre sí ordenadamente contribuyen a determinado objeto. ${ }^{1}$

También se define como el conjunto de principios, normas o reglas, lógicamente enlazados entre sí, acerca de una ciencia o materia. Ordenado y armónico conjunto que contribuye a una finalidad. Método. Procedimiento. Técnica. Doctrina. ${ }^{2}$

De acuerdo a estas definiciones básicas tenemos una serie de sistemas como el sistema planetario que se estructura con el sol sus planetas, sus satélites y cometas, el sistema visual que consiste en el conjunto de órganos como la retina, pupila y el nervio óptico que hacen posible la visión en el ser humano, el sistema de los elementos químicos por orden atómico entre otros.

Carla Huerta Ochoa sostiene concebir al derecho como un sistema jurídico significa que sus elementos se interrelacionan para formar una unidad, lo cual es indispensable para entender su funcionamiento; esto supone una estructura que determina su operatividad. ${ }^{3}$

Por su parte Nuria Gonzales citando a Humberto Zarate y otros definen al sistema jurídico como aquel conjunto articulado y coherente de instituciones, métodos, procedimientos y reglas legales que constituyen el derecho positivo en un lugar y tiempo determinado. ${ }^{4}$

De las definiciones mencionadas se podría definir al Sistema Aduanero del Perú como el conjunto de principios, reglas, pautas, ordenamientos, procedimientos, métodos, instrumentos jurídicos y demás disposiciones articulados y coherentes relacionados lógicamente entre sí

Diccionario de la Lengua Española. Real Academia de la Lengua. Vigésima Segunda Edición. Tomo 9. p.1408

CABANELLAS. Guillermo: Diccionario Enciclopédico de Derecho Usual. Editorial Heliasta.S.R.L. República Argentina. 1989. Tomo VII. P. 449

3 HUERTA OCHOA. Carla: Teoría del Derecho. Cuestiones Relevantes. UNAM. Instituto e Investigaciones Jurídicas. Primera Edición 2009. México. P. 29

4 GONZALES MARTIN. Nuria. Sistemas Jurídicos Contemporáneos. UNAM. Instituto de Investigaciones Jurídicas. Primera edición 2010. P.23 
que tienen por objeto regular el tráfico internacional de mercancías, personas y medios de transporte que ingresan y salen del territorio aduanero peruano.

En el Perú la Constitución Política del Estado, la Ley General de Aduanas conjuntamente con la reglamentación aduanera especializada regulan la actividad y operatividad aduanera.

Es importante mencionar que también forman parte de la estructura de éste sistema una serie de Tratados internacionales suscritos por el Perú referidos a las preferencias arancelarias, reglas de origen, valoración aduanera, nomenclatura aduanera y otros convenios internacionales direccionados al mejoramiento de la actividad aduanera y nuestro comercio exterior, adicionadas a estos instrumentos internacionales se integran las leyes decretos, resoluciones y circulares que regulan la actividad aduanera.

Como es por todos sabido, todo el orden jurídico de nuestra nación se desprende o está en concordancia con nuestra Constitución Política, a razón de esto, es de hacer mencionar en primer plano, dando el lugar jerárquico normativo a la Constitución Política de nuestro país, tomando los artículos y disposiciones relacionadas con el ambiente jurídico aduanero.

En el mundo es poco común que las Constituciones Políticas de los países contengan normas con incidencia directa en los aspectos aduaneros, sin embargo en el Perú la Constitución Política de 1993 en su inciso 20) del artículo 118 otorga facultad al Presidente de la República (Jefe de Gobierno) para regular las Tarifas arancelarias.

Esta facultad está dada al Presidente de la República por la necesidad de modificar con suma urgencia los niveles arancelarios ya sea por razones de política comercial, política fiscal o política industrial.

Esta situación de la rapidez en el cambio no podría darse en el Congreso de la República dada su procedimiento poco ágil, lento y hasta pesado por sus debates y aprobación de una ley.

Por otro lado el artículo 74 de la misma Carta Política establece en su parte pertinente que los tributos, se crean, modifican o derogan o se establece una exoneración, exclusivamente por ley o decreto legislativo en caso de delegación de facultades, salvo los aranceles y tasas, los cuales se regulan mediante decreto supremo.

El referido artículo establece el Principio de Reserva de la Ley precisando una salvedad o excepción a éste principio tratándose de "aranceles" referidos a los derechos arancelarios como impuestos que gravan directamente a la importación al consumo de las mercancías e indirectamente a la admisión temporal. Comprendida en esta última a los regímenes aduaneros de Admisión temporal para perfeccionamiento activo y admisión temporal para reexportación en el mismo estado.

En armonía con lo señalado en párrafos anteriores la Ley General de Aduanas vigente, aprobada por Decreto Legislativo $\mathrm{N}^{\circ} 1053$, en su artículo primero dispone que aquella tiene 
por objeto regular la relación jurídica que se establece entre la Superintendencia Nacional de Aduanas y Administración Tributaria - SUNAT y las personas naturales y jurídicas que intervienen en el ingreso, permanencia, traslado y salida de las mercancías hacia y desde el territorio aduanero, generándose una obligación aduanera considerada como una obligación género que abarca a todos los regímenes aduaneros y entendida como el sometimiento de la mercancía en tráfico internacional al control aduanero se genere o no tributos.

En los regímenes aduaneros son sujetos todas las personas que actúan de cualquier forma en el tráfico de mercancías, quiere decir, transportistas, almacenistas, agentes de aduanas, consignatarios, exportadores. Las funciones derechos y obligaciones de estos sujetos están reguladas por la legislación aduanera.

Es preciso mencionar entonces la participación de los operadores de comercio exterior como cualquier persona natural y jurídica interviniente o beneficiaria, por si o por otro, en los regímenes aduaneros previstos en la ley sin excepción alguna. Son operadores de comercio exterior los despachadores de aduanas que comprende a los dueños, consignantes y consignatarios, los despachadores oficiales y los agentes de aduanas, luego tenemos a los transportistas o sus representantes, los agentes de carga internacional, los almacenes aduaneros, empresas de servicio postal, empresas de servicio de entrega rápida, almacenes libres (Duty free), beneficiarios de material de uso aeronáutico y el operador económico autorizado.

Existe toda una numerosa legislación aduanera dinámica que cambia constantemente por los cambios permanentes del comercio exterior, que integran una estructura normativa que regula el control, facilitación, fiscalización y recaudación del ingreso y salida de mercancías, personas y medios de transporte del territorio aduanero nacional hacía otro territorio aduanero internacional.

Dicha estructura está integrada por los diferentes tipos normativos que racionalmente se relacionan y se enlazan entre si dando lugar a lo que consideremos un Sistema Normativo Aduanero del Perú, habiendo considerado las normas fundamentales, normas especiales, normas complementarias, normas supletorias y normas modificatorias.

En este sentido, el Sistema Normativo Aduanero del Perú es un importante sistema empleado en nuestro país y en el extranjero en el contexto del comercio exterior, las disposiciones que norman y operan han tenido incesantes cambios que a continuación detallo someramente: 


\section{ESTRUCTURA NORMATIVA:}

1. Normas Fundamentales:

\subsection{LEYES Y DECRETOS}

\subsubsection{Ley General de Aduanas.}

Decreto Legislativo No 1053

Publicación: 27.06.2008.

Vigencia: 17.03.2009 parcialmente de acuerdo a su reglamento.

Decreto Legislativo $N^{\circ} 1109$

Publicación: 20.06.12

Decreto Legislativo $\mathrm{N}^{\circ} 1122$

Publicado: 18.07.12

Ley No 29973 LEY GENERAL DE LA PERSONA CON DISCAPACIDAD

Publicado: 24.12.12

Ley No 30028 LEY QUE MODIFICA EL ART. 140

Publicado: 07.06.13

Ley N $^{\circ} 30131$ LEY QUE AUTORIZA A LA SUNAT A DISPONER DE MERCANCIAS

Publicado 19. 12. 13

\subsubsection{Reglamento de la Ley General de Aduanas}

Decreto Supremo No 245-2013-EF

Publicado 01.10.2013.

Vigencia: 11.10.13

\subsubsection{Tabla de Sanciones e Infracciones}

D. S. No 031-2009-EF

Publicación: 11.02.2009

Vigencia: 17.03.2009

\subsubsection{Fusión de SUNAT con ADUANAS}

Decreto Supremo No 061-2002-PCM

\subsubsection{Reglamento de Organización y Funciones de la SUNAT}


ROF - Reglamento de Organización y Funciones de la SUNAT DS 115-2002PCM

Modificación del Reglamento de Organización y Funciones de la

Superintendencia Nacional de Aduanas y de Administración Tributaria - SUNAT,

R.S. N 188-2015/SUNAT - Anexo1 - Anexo 2 (vigente)

1.1.6 Arancel de Aduanas y sus Normas Complementarias

Decreto Supremo No 017-2007-EF

Decreto Supremo No 238-2011-EF

1. 2. Convenios y Acuerdos Internacionales:

1.2.1.- Tratados Bilaterales

A.-COMUNIDAD ANDINA DE NACIONES (CA)

Convenios Perú - Bolivia.

Convenios Perú - Colombia.

Convenios Perú - Ecuador.

Convenios Perú - Venezuela.

B.- Asociación Latinoamericana de Integración (ALADI).

Acuerdos suscritos

Argentina Brasil Chile Cuba México Paraguay Uruguay

C.- Acuerdo de Promoción Comercial Perú - EEUU.

D.- Tratado de Libre Comercio Perú - Canadá.

E.- Acuerdo de Libre Comercio Perú - Singapur.

F.- Acuerdo entre el Gobierno de la República Popular China y el Gobierno de la República del Perú referente a la Cooperación y Asistencia Administrativa mutua en asuntos Aduaneros.

G. Otros Convenios Bilaterales Específicos:

- Convenio sobre Tránsito de Personas y vehículos, Anexo 02 del Acuerdo Amplio Peruano - Ecuatoriano de Integración Fronteriza, Desarrollo y Vecindad.

- Convenio sobre Régimen Uniforme de Ferias Fronterizas con Ecuador.

- Tratado de comercio y Navegación con Ecuador.

- El Convenio de Tránsito Perú - Boliviano de 1948 
- Procedimiento para el Tránsito Internacional de Mercancías de Bolivia a través del Perú (TIM).

- Convenio entre los Gobiernos de Perú y Bolivia sobre la Participación de Bolivia en la Zona Franca Turística de Playa en Ilo.

- Tratado y Protocolo Complementario para resolver la cuestión de Tacna y Arica, suscrito en 1929 suscrito entre Perú - Chile.

- Convención entre Perú - Chile sobre Libre Tránsito de Mercancías.

\subsubsection{Organismos Internacionales}

a) La Organización Mundial de Comercio (OMC)

b) La Organización Mundial de Aduanas (OMA)

c) La Asociación Latinoamericana de Integración (ALADI)

d) La Comunidad Andina de Naciones (CAN)

e) Otras Entidades Internacionales en Materia Aduanera.

- La Cámara de Comercio Internacional (CCI)

- El Área de Libre Comercio de las Américas (ALCA)

- El Foro de Cooperación Económica de Asia y el Pacifico- APEC

2. Normas Especiales:

a) Ley de los Delitos Aduaneros

Ley No 28008. (18.06.2003)

Decreto Legislativo $\mathrm{N}^{\circ} 1111$

Publicación: 29.06.12

Decreto Legislativo $\mathrm{N}^{\circ} 1122$

Publicación: 18.07.12

b) Reglamento de la Ley de los Delitos

D. S. No 121-2003-EF (27.08.2003)

D. S. No 164-2012-EF (29.08.2012)

C) Valoración de Mercancías:

- Acuerdo Relativo a la aplicación del Artículo VII del Acuerdo General sobre Aranceles Aduaneros y Comercio de 1994 
- Reglamento para la Valoración de Mercancías según el Acuerdo de Valoración de la $\mathrm{OMC}$

\section{Decreto Supremo No 186-99-EF}

- Modifica el Reglamento para la Valoración

\section{Normas Complementarias:}

\section{- CONTENEDORES}

A. Reglamento de Contenedores

Decreto Supremo No 078-2015-EF

B. Procedimiento de ingreso y salida de contenedores

Resolución: 002126 (15/12/98) INTA-PG.21

- Ferias Internacionales

A. Ley General de Ferias y Exposiciones Internacionales en el país

Decreto Ley No 21700 (24.11.76)

B. Reglamento de la Ley General de Ferias y Exposiciones Internacionales Decreto Supremo N. ${ }^{\circ} 006-77-C O / C E(01 / 4 / 1977)$.

C. Reglamento Aduanero para Ferias y Exposiciones Internacionales

Decreto Supremo No 094-79-EF (15/7/1979)

D. Procedimientos de Ferias o Exposiciones Internacionales

Resolución Nº 0007 (09/01/2010) - INTA-PG.15.

- Equipajes y Menaje de Casa

A. Reglamento de Equipajes y Menaje de Casa

D. S. 016-2006-EF (15/02/2006)

D.S. 182-2013-EF (25/07/2013)

B. Cartilla de Valores Mínimos Referenciales para el despacho de mercancías que constituyan menaje de casa, envíos o paquetes postales y obsequios y sus Reglas de Aplicación RESOLUCION DE SUPERINTENDENCIA DE ADUANAS No $000002(09.01 .99)$

\section{- Vehículos para turismo}

A. Convenio de Nueva York Convención sobre formalidades aduaneras para la importación temporal de vehículos particulares de carretera 
B. Reglamento de Internamiento Temporal de Vehículos con fines turísticos Decreto Supremo No 015-87-ICTI/TUR

C. Reconocimiento del "Carnet de Passages en Douannes" o libreta de pasos por aduanas Decreto Supremo de fecha 18 .11.1942

D. Procedimiento de Vehículos para Turismo

Resolución de Intendencia Nacional de Aduanas No 000 ADT/2000-003521 de

fecha16 .11.2000 que modifica el INTA-PG.16 (v.2)

\section{- Envíos o Paquetes transportados por concesionarios postales}

A. Reglamento de la Destinación Aduanera Especial de Envíos o Paquetes transportados por concesionarios postales,

Decreto Supremo No 031-2001-EF 23.02.2001 modificado por Decreto Supremo 158-2001-EF

B. Nuevo Reglamento de los Destinos Aduaneros Especiales del Servicio Postal y del Servicio De Mensajería Internacional

Decreto Supremo No 067-2006-EF

C. Procedimiento de destino especial de envíos o paquetes transportados por

Concesionarios postales

RIN 002126 INTA PG.13 (07.12 98) y modificatorias

RIN 00162 INTA-PE.13.02 (30.03.2012)

D. Procedimiento de Envíos Postales Transportados por el Servicio Postal

Resolución: 410/2013 (31.12.2013) - INTA-PG.13

* CETICOS

A. Ley de CETICOS (Centro de Exportación, Transformación, Industria, Comercialización y Servicios en Ilo, Matarani y Tacna)

Ley No 26831 que modifica los D. Legislativo No 842, 864 y 865 aprobado por Decreto Supremo No 112-97-EF 03-09-97

B. Procedimiento para la realización de actividades de maquila y ensamblaje en los CETICOS D.S. N ${ }^{\circ}$ 112-2005-EF (04.09. 2005 
C. Ley que regula el traslado de mercancías con destino a la ZOFRATACNA, los CETICOS y terceros países Ley No 28528 (25.05.2005)

- Franquicia Diplomática,

A. Franquicia Diplomática,

Decreto Legislativo No 550 (24.11.1989)

B. Ley de Importación de vehículos para misiones diplomáticas y organismos internaciones,

Ley No 26983 (25.10.1998)

C. Reglamento de la Ley No 26983

Decreto Supremo No 112-98-EF (04.12.1998),

D. FRANQUICIA ADUANERA DIPLOMATICA VEHICULAR AL AMPARO DE LA LEY N²6983

INTA-PE.01.24 (15.10.2010)

- Reglamento sobre el arribo y zarpe de naves, D. S. No 036-72-TC (29 Dic.1999)

- Procedimientos Generales Administrativos de Cobranzas Administrativas, Reclamos Tributarios y Devoluciones de pagos indebido o en exceso

- Procedimiento Cobranzas Administrativas. RSNAA-000581-2003, (05.01.2004)

- Reclamos Tributarios, RSNAA-000581-2003,(05.01.2004) Aprueban nueva versión de Procedimiento INPCFA-PG.04 (antes IFGRA-PG.04)

- Devoluciones de pagos indebido o en exceso, con RSNAA-0070-2010-SUNAT/A, (13.02.2010) Aprueban nueva codificación y descripción del procedimiento de Devoluciones por Pagos Indebidos o en Exceso INPCFA-PG.05 (antes IFGRAPG.05)

- Ley de Rotulado de Productos Industriales Manufacturados (Ley No 28405) y su Reglamento aprobado por D.S. N 020-2005-PRODUCE.

- Ley de Medidas en Frontera para la protección de los Derechos de Autor y Derechos Conexos y los Derechos de Marcas (D.LEG. $N^{\circ}$ 1092) Y SU REGLAMENTO APROBADO POR D.S. N 009-2003-EF. 
IMPORTACIÓN PARA EL CONSUMO

INTA.PG-01-A

\begin{tabular}{|c|c|c|c|}
\hline$N^{0}$ Resolución & Asunto & $\begin{array}{c}\text { FECHA } \\
\text { VIGENCIA }\end{array}$ & Estado \\
\hline $491 / 2010$ & $\begin{array}{l}\text { APRUEBA PROCEDIMIENTO GENERAL "IMPORTACION PARA EL } \\
\text { CONSUMO INTA-PG.01-A(V.T) } \\
\text { Dejan sin efecto la versión } 4 \text { del Procedimiento Especifico "Sistema } \\
\text { Anticipado de Despacho Aduanero de Importación para el Consumo" - } \\
\text { INTA-PE,01.17 } \\
\text { Dejan sin efecto el Procedimiento Especifico "Despacho Anticipado de } \\
\text { Importación para el Consumo en las Aduanas Marítima y Aérea del } \\
\text { Callao" inta-pe.01.17-a versión } 1\end{array}$ & $\begin{array}{l}\text { 31/08/2010 para } \\
\text { Arequipa Chiclayo. } \\
\text { Cusco. Iquitos.Pucallpa. } \\
\text { Puerto Maldonado Puno. } \\
\text { Tacna. Tarapoto } \\
\text { Tumbes. Agencia } \\
\text { Aduanera La Tina. } \\
\text { 20/09/2010 para } \\
\text { Maríima Callao. } \\
\text { 30/09/2010 para Postal } \\
\text { Callao }\end{array}$ & DEROGADO \\
\hline $583 / 2010$ & $\begin{array}{l}\text { Modifíquese el numeral } 50 \text { del literal A de la Sección Vil del Procedimiento } \\
\text { General importación para el Consumo" INTA-PG } 01 \text { - A (versión 1) }\end{array}$ & 03/12/2010 & DEROGADO \\
\hline 005 / 2011 & $\begin{array}{l}\text { Modifican Procedimiento General IMPORTACIÓN PARA EL CONSUMO" } \\
\text { INTA-PG.1-A (versión } 1 \mathrm{i}\end{array}$ & $13 / 01 / 2011$ & DEROGADO \\
\hline $440 / 2011$ & $\begin{array}{l}\text { Modifican Procedimiento General IMPORTACION PARA EL CONSUMO* } \\
\text { INTA-PG 1-A eversión } 11\end{array}$ & 05/12/2011 & DEROGADO \\
\hline 342 / 2012 & $\begin{array}{l}\text { Modifican Procedimiento General MPORTACION PARA EL CONSUMO" } \\
\text { INTA-PG J-A (versión 1) }\end{array}$ & 06/08/2012 & DEROGADO \\
\hline $400 / 2012$ & $\begin{array}{l}\text { Modifican Procedimiento General IMPORTACIÓN PARA EL CONSUMO* } \\
\text { INTA-PG.01-A (versión 1) }\end{array}$ & $\begin{array}{l}\text { La presente Resolución } \\
\text { entrará en vigencia a } \\
\text { partir del } 20 \text { de agosto } \\
\text { de 2012. excepto el } \\
\text { artículo primero que } \\
\text { entrará en vigencia a } \\
\text { partir del día siguiente } \\
\text { de su publicación el } \\
\text { 19/08/2012 }\end{array}$ & DEROGADO \\
\hline $0273 / 2013$ & $\begin{array}{l}\text { Modifican Procedimiento General IMPORTACIÓN PARA EL CONSUMO* } \\
\text { INTA-PG.01-A (versión 1) }\end{array}$ & $11 / 10 / 2013$ & DEROGADO \\
\hline $415 / 2013$ & $\begin{array}{l}\text { Modifican Procedimiento General IMPORTACIÓN PARA EL CONSUMO" } \\
\text { INTA-PG.01-A (versión 1) }\end{array}$ & $\begin{array}{l}\text { La presente Resolución } \\
\text { entrará en vigencia a } \\
\text { partir del día siguiente } \\
\text { de su publicación con } \\
\text { excepción de los } \\
\text { artículos } 6^{\circ} .9^{\prime} .10^{\circ} 15^{\prime \prime} . \\
17^{\circ}, 18^{\circ}, 20^{\circ} \text { y } 22^{\circ} \text { que } \\
\text { entrarán en vigencia el } \\
15 / 01 / 2014 \text {. }\end{array}$ & DEROGADO \\
\hline $10 / 2015$ & $\begin{array}{l}\text { Aprueban del Procedimiento General IMPORTACION PARA EL } \\
\text { CONSUMO" INTA-PG.01-A (versión 2) }\end{array}$ & $30 / 06 / 2015$ & VIGENTE \\
\hline
\end{tabular}


MANIFIESTO DE CARGA

INTA-PG.09

\begin{tabular}{|c|c|c|c|}
\hline $\mathrm{N}^{\circ}$ Resolución & Asunto & $\begin{array}{l}\text { Fechal } \\
\text { Vigencia }\end{array}$ & Estado \\
\hline $1195 / 1999$ & Modificación del Procedimiento INTA-PG.09 & 04/10/1999 & Derogado \\
\hline $1758 / 1999$ & Modificación del Procedimiento INTA-PG.09 & 03/12/1999 & Derogado \\
\hline $0437 / 2000$ & Modificación del Procedimiento INTA-PG.09 & $04 / 02 / 2000$ & Derogado \\
\hline $3513 / 2000$ & Modificación del Procedimiento INTA-PG.09 & 20/11/2000 & Derogado \\
\hline $1642 / 2001$ & Modificación del Procedimiento INTA-PG.09 & 01/08/2001 & Derogado \\
\hline 1694 / 2002 & Modificación del Procedimiento INTA-PG.09 & 08/09/2002 & Derogado \\
\hline $0281 / 2003$ & Modificación del Procedimiento INTA-PG.09 & $02 / 08 / 2003$ & Derogado \\
\hline $0541 / 2003$ & Aprueban Versión 3 del Procedimiento INTA-PG 09 & $13 / 01 / 2004$ & Derogado \\
\hline $0085 / 2008$ & Modificación Versión 3 del Procedimiento INTA-PG 09 & $17 / 02 / 2004$ & Derogado \\
\hline $0109 / 2008$ & $\begin{array}{l}\text { Precisan Transmisión de la relación detallada y DUIM prevista en el } \\
\text { Procedimiento INTA-PG-09 }\end{array}$ & 02/03/2008 & Derogado \\
\hline $0192 / 2008$ & $\begin{array}{l}\text { Prorrogan Periodo de transmisión piloto dispuesto en la Resolución de } \\
\text { Superintendencia Nacional Adjunta de Aduanas } N^{\circ} \text { 109-2008/SUNAT/A }\end{array}$ & $12 / 04 / 2008$ & Derogado \\
\hline $0245 / 2008$ & $\begin{array}{l}\text { Dictan disposiciones sobre el Procedimiento de Manifiesto de carga INTA- } \\
\text { PG } 09 \text { (versión 3) y sus específicos }\end{array}$ & 09/05/2008 & Derogado \\
\hline $0353 / 2010$ & Modifican Procedimiento General "Manifiesto de Carga" - INTA-PG 09 (v3) & $12 / 06 / 2010$ & Derogado \\
\hline $066 / 2010$ & Aprueba versión 4 del Procedimiento INTA.PG.09 & $\begin{array}{l}\text { Conforme a lo dispuesto por el } \\
\text { artículo } 2^{\circ} \text { del Decreto Supremo } \\
\mathrm{N}^{\circ} 10-2009-E F \text {, modificado por } \\
\text { Decreto Supremo } \mathrm{N}^{\circ} 319-2009- \\
\mathrm{EF} \text {, con excepción de los incisos } \\
\mathrm{c} \text { ) al i) del numeral } 1 \text { del literal } \mathrm{A} \\
\text { y numerales } 1,3 \text { e incisos c) al i) } \\
\text { del numeral } 5 \text { del literal B de la } \\
\text { Sección VII que entrara en } \\
\text { vigencia el } 1 \text { de enero de } 2011\end{array}$ & Derogado \\
\hline $500 / 2010$ & Aprueba versión 5 del Procedimiento INTA.PG.09 & $\begin{array}{l}\text { 30/08/2010 para llo, Paita, } \\
\text { Chimbote, Mollendo, Pisco y } \\
\text { Salaverry, 31/08/2010 para } \\
\text { Arequipa, Chiclayo, Cusco, } \\
\text { Iquitos, Pucallpa, Puerto } \\
\text { Maldonado, Puno, Tacna, } \\
\text { Tarapoto, Tumbes, Agencia } \\
\text { Aduanera La Tina, 20/09/2010 } \\
\text { para Marítima del Callao, } \\
\text { 27/09/2010 para Aérea Callao y } \\
\text { 01/10//2010 para Postal Callao }\end{array}$ & Vigente \\
\hline
\end{tabular}


LEGAJAMIENTO

INTA PE-00.07

\begin{tabular}{|c|c|c|c|}
\hline$N^{\circ}$ Resolución & Asunto & $\begin{array}{l}\text { Fecha de } \\
\text { Vigencia }\end{array}$ & Estado \\
\hline $0525 / 2003$ & Aprueban versión 2 del INTA-PE.00.07 & 09/12/2003 & No vigente \\
\hline $0042 / 2010$ & $\begin{array}{l}\text { Aprueban versión } 3 \text { Él procedimiento especifico LEGAJAMIENTO 0E LA DECLARACION - } \\
\text { iNTA-PE.00.07 }\end{array}$ & 01/06/2010 & Vigente \\
\hline $01 / 2015$ & Prorrogan ¡a entrada en vigencia de! ciertas Resoluciones de Intendencia Nacional & $12 / 01 / 2015$ & Vigente \\
\hline $08 / 2015$ & $\begin{array}{l}\text { Precisan las fechas de entrada en vigencia en la Intendencia de Aduana Manta del } \\
\text { Callao de diversas Resoluciones de Intendencia Nacional sepias modalidades de } \\
\text { despacho }\end{array}$ & $11 / 04 / 2015$ & Vigente \\
\hline
\end{tabular}

\section{DEVOLUCIÓN DE BULTOS SOBRANTES Y BULTOS DESEMBARCADOS POR ERROR INTA PE-09.01}

\begin{tabular}{|c|l|l|}
\hline \multirow{2}{*}{$N^{\circ}$ Resolución } & Asunto & \multicolumn{1}{c|}{$\begin{array}{c}\text { Fecha de } \\
\text { Vigencia }\end{array}$} \\
\hline $0541 / 2003$ & Aprobación del procedimiento INTA-PE.09.01 V',2 ssgun RSNM D541-2003 & Caducado \\
\hline $051 / 2 \mathrm{G} 10$ & Aprobación del procedimiento INTA-PE.09.01 V.3 según RSNM 051-2010 & $\begin{array}{l}31 / 08 / 2010 \text { para Arequipa, } \\
\text { Chiclayo, Cusco, Iquitos. } \\
\text { Pucallpa, Puerto } \\
\text { Maldonado, Puno. Tacna } \\
\text { Agencia de Aduana La } \\
\text { Tina el 20/09/2010 para } \\
\text { marina del callao, el } \\
27 / 09 / 2010 \text { para Aerea } \\
\text { Callao y 01/10/2010 para } \\
\text { Postal Callao }\end{array}$ \\
\hline
\end{tabular}

MEDIANTE RSNAA N 051-2010/SUNAT/A se aprobó el Procedimiento Especifico Devolución de Bultos Sobrantes INTA PE.09.01. (Versión 3); siendo importante lo siguiente:

\begin{tabular}{|l|l|l|l|l|}
\hline \multicolumn{1}{|c|}{ Código } & \multicolumn{1}{|c|}{ Procedimiento } & Publicación & Vigencia & \multicolumn{1}{|c|}{ Aduana } \\
\hline & $\begin{array}{l}\text { PROCEDIMIENTO ESPECIFICO “DEVOLUCIÓN DE BULTOS } \\
\text { SOBRANTES (V3) }\end{array}$ & 04.02 .2010 & 02.02 .2010 & Ilo y Paita \\
\hline & & & 08.03 .2010 & $\begin{array}{l}\text { Chimbote, Mollendo, Pisco y } \\
\text { Salaverry }\end{array}$ \\
\hline INTA PE 09.01 & & $\begin{array}{l}\text { Arequipa, Chiclayo, Cusco, } \\
\text { Iquitos, Pucallpa, Puerto } \\
\text { Maldonado, Puno, Tacna, } \\
\text { Tarapoto, Tumbes, Agencia } \\
\text { Aduanera la Tina }\end{array}$ \\
\hline & & & 20.09 .2010 & Marítima del Callao \\
\hline & & & 27.09 .2010 & Aérea del Callao \\
\hline
\end{tabular}




\section{RECTIFICACIONES DE ERRORES DEL MANIFIESTO INTA PE-09.02}

\begin{tabular}{|c|c|c|c|}
\hline$N^{\circ}$ Resolución & Asunto & Vigencia & Estado \\
\hline $0437 / 2000$ & Modificación según Resolución 0437-2000 & $04 / 02 / 2000$ & Derogado \\
\hline $3513 / 2000$ & Meditación del procedimiento segué Resolución 3513-2000 & $27 / 11 / 200$ & Derogado \\
\hline $0541 / 2003$ & aprueba V.2 del procedimiento según Resolución 0541-2003 & $13 / 01 / 2004$ & Derogado \\
\hline $558 / 2010$ & Aprueba V.4 del procedimiento según Resolución 558-2010 & $\begin{array}{l}\text { 22/09/2010 para llo. Paita. } \\
\text { Chimbote, Mollendo. Pisco, } \\
\text { Salaverry, Arequipa, Chiclayo, } \\
\text { Cusco, Iquitos, Pucallpa, } \\
\text { Puerto Maldonado, Puno, } \\
\text { Tacna, Tarapoto, Tumbes, } \\
\text { Marítima del Callao y Agencia } \\
\text { Aduanera la Tina el } \\
\text { 27/09/2010 y 01/10/2010 para } \\
\text { Postal del Callao }\end{array}$ & Derogado \\
\hline $0397 / 2012$ & $\begin{array}{l}\text { Medican Procedimiento Especifico "Rectificación de Errores e Incorporación } \\
\text { de Documentos de Transporte al Manifiesto de Carga "INTA PG.09.02 (V.4) }\end{array}$ & $18 / 08 / 2012$ & Derogado \\
\hline $12 / 2013$ & $\begin{array}{l}\text { Aprueban Procedimiento Especio de 'Rectificación del Manifiesto de Carga } \\
\text { y Operaciones Asedadas" 1NTA-PE.09.02 } \\
\text { (versión 5) }\end{array}$ & $\begin{array}{l}\text { A partir del 09/12/2013. } \\
\text { Excepto para la jurisdicción de } \\
\text { la Intendencia de Aduana } \\
\text { Marítima del Callao en la cual } \\
\text { entrará en vigencia el } \\
03 / 02 / 2014 \text {. }\end{array}$ & Vigente \\
\hline $11 / 2015$ & $\begin{array}{l}\text { Aprueban medicaciones al procedimiento especifico de "Reeducación del } \\
\text { Manifiesto de Carga y Operaciones Asodadas-INTA-PE.09.02 } \\
\text { versión 5; }\end{array}$ & 05/07/2015 & Vigente \\
\hline
\end{tabular}

\section{RETORNO DE MERCANCÍAS \\ INTA-PE.02.02}

\begin{tabular}{|c|l|c|c|}
\hline$N^{\circ}$ Resolución & \multicolumn{1}{|c|}{ Asunto } & Vigencia & Estado \\
\hline $\mathbf{1 1 9 5} / \mathbf{1 9 9 9}$ & Modificación del INTA-PE.02.02 según resolución & $04 / 10 / 1999$ & Derogado \\
\hline $\mathbf{1 3 2 9} / \mathbf{1 0}$ & Modificación del INTA-PE.02.02 & $12 / 15 / 2000$ & Derogado \\
\hline $\mathbf{0 5 3 9} / \mathbf{1 3}$ & Aprueba versión 2 del INTA-PE.02.02 & $11 / 12 / 2003$ & Derogado \\
\hline $\mathbf{0 4 0} / \mathbf{2 0 1 0}$ & $\begin{array}{l}\text { Aprueban versión procedimiento INTA-PE.02.02 } \text { Retorno de Mercancías/Reingreso • } \\
\text { Salida }\end{array}$ & $04 / 02 / 2010$ & Vigente \\
\hline
\end{tabular}




\section{EXPORTACIÓN DEFINITIVA}

INTA PG.02

\begin{tabular}{|c|c|c|c|}
\hline$N^{\circ}$ Resolución & Asunto & VIGENCIA & Estado \\
\hline 0984 / 1999 & Procedimiento de aportación Definitiva & $27 / 05 / 1999$ & Derogado \\
\hline $1195 / 1999$ & Procedimiento de Exportación Definitiva & 04/10/1999 & Derogado \\
\hline $2120 / 1999$ & Procedimiento de Exportación Definitiva & $31 / 12 / 1999$ & Derogado \\
\hline $1829 / 2000$ & Procedimiento de Exportación Definitiva & $01 / 07 / 2000$ & Derogado \\
\hline 2127 / 2001 & Procedimiento de Exportación Definitiva & $22 / 09 / 2001$ & Derogado \\
\hline 0657 / 2002 & Procedimiento de Exportación Definitiva & $09 / 04 / 2002$ & Derogado \\
\hline $1103 / 2002$ & Procedimiento de E>portación Definitiva & $17 / 05 / 2002$ & Derogado \\
\hline $2459 / 2002$ & Procedimiento de Exportación Definitiva & $06 / 01 / 2093$ & Derogado \\
\hline $0373 / 2003$ & Procedimiento de Exportación Definitiva & $30 / 08 / 2003$ & Derogado \\
\hline $0539 / 2003$ & Procedimiento de Exportación Definitiva & $11 / 12 / 2003$ & Derogado \\
\hline $0440 / 2005$ & Procedimiento de Exportación Definitiva Versión 5 & $16 / 01 / 2005$ & Derogado \\
\hline 0137 / 2009 & Aprueban Procedimiento de Exportación Definitiva INTA-PG.02 (Versión 6) & $17 / 03 / 2009$ & Vigente \\
\hline $0335 / 2009$ & Modifican Procedimiento de Exportación Definitiva INTA-PG.02 (V.6) & $20 / 07 / 2009$ & Vigente \\
\hline $0369 / 2009$ & $\begin{array}{l}\text { Prorrogan la entrada en vigencia de la transmisión de los Documentos Digitalizados a } \\
\text { que se refiere el Procedimiento de Exportación Definitiva INTA-PG } 02 \text { v.6) }\end{array}$ & $21 / 07 / 2009$ & Vigente \\
\hline $0212 / 2013$ & Modifican Procedimiento de E-portalón Definitiva INTA-PG.02 (V.6) & $31 / 08 / 2013$ & Vigente \\
\hline $118 / 2014$ & Modifican Procedimiento de Exportación Definitiva INTA-PG.02 (V.6) & $27 / 03 / 2014$ & Vigente \\
\hline $09 / 2015$ & Modifican Procedimiento de Exportación Definitiva INTA-PG.02 (V.6) & $29 / 05 / 2015$ & Vigente \\
\hline
\end{tabular}

\section{DEUDA DE RECUPERACIÓN ONEROSA} INPCFA-PE.02.05

\begin{tabular}{|c|l|c|c|}
\hline$N^{\circ}$ Resolución & \multicolumn{1}{|c|}{ Asunto } & VIGENCIA & Estado \\
\hline $\mathbf{0 9 9 7 / 1 9 9 9}$ & Aprueban Procedimiento Especio INRA-PE.03 Deudas de Recuperación Onerosa & $04 / 10 / 1999$ & vigente \\
\hline $\mathbf{0 1 1 1} / \mathbf{2 G 0 1}$ & $\begin{array}{l}\text { Modifican Procedimiento Especifico INRA-PE.03 Deudas de Recuperación Onerosa, } \\
\text { recodificado como ÍFGRA-PE.10 con RSNM IT 000475-2003 / SUNAT/A del } \\
23.10 .2003\end{array}$ & $03 / 07 / 2001$ & vigente \\
\hline $\mathbf{0 1 7 1} / \mathbf{2 0 1 3}$ & $\begin{array}{l}\text { Aprueba codificación del procedimiento 1FGRA-PE.10 como INPCFA-PE.02.05 } \\
\text { Deudas de Recuperación Onerosa }\end{array}$ & $20 / 07 / 2013$ & Vigente \\
\hline $\mathbf{0 2 5 6}$ / 2013 & $\begin{array}{l}\text { Modifican Procedimiento Específico ¡NPCFA-PE.02.05 Deudas de Recuperación } \\
\text { Onerosa" (versión 1) }\end{array}$ & $04 / 10 / 2013$ & Vigente \\
\hline
\end{tabular}




\section{DEVOLUCIONES POR PAGOS INDEBIDOS O EN EXCESO YIO COMPENSACIONES DE DEUDAS TRIBUTARIAS ADUANERAS INPCFA-PG.05}

\begin{tabular}{|c|c|c|c|}
\hline$N^{\circ}$ Resolución & Asunto & Vigencia & Estado \\
\hline $0581 / 2003$ & Aprueban Procedimiento IFGRA-PG 05 versión 1 & 05/01/2004 & Derogada \\
\hline $0323 / 2006$ & Aprueban versión 2 del Procedimiento IFGRA-PG.05 & $14 / 06 / 2006$ & Derogada \\
\hline $0051 / 2007$ & Modifican Procedimiento IFGRA-PG.05 versión 2 & 02/02/2007 & Derogada \\
\hline $0328 / 2007$ & Modifican Procedimiento IFGRA-PG.05 versión 2 & 08/06/2007 & Derogada \\
\hline $0070 / 2010$ & $\begin{array}{l}\text { Aprueba nueva codificación y descripción del procedimiento de Devoluciones por } \\
\text { Pagos Indebidos o en Exceso (IFGRA-PG.05) y el de Compensaciones ¡IFGRA- } \\
\text { PE17) que se deroga e incorpora a la versión } 3 \text { del procedimiento general IFGRA- } \\
\text { PG.05 identificándolo como Devoluciones por Pagos Indebidos o en Exceso y/o } \\
\text { Compensaciones de Deudas Tributarias Aduaneras }\end{array}$ & $13 / 02 / 2010$ & Vigente \\
\hline $0184 / 2012$ & Modifican Procedimiento IFGRA-PG 05 versión 3 & $22 / 04 / 2012$ & Vigente \\
\hline $0171 / 2013$ & $\begin{array}{l}\text { Aprueba codificación del procedimiento IFGRA-PG.05 como INPCFA-PG.05 } \\
\text { Devoluciones de Pagos Indebidos o en Exceso yo Compensaciones de Deudas } \\
\text { Tributarias Aduaneras }\end{array}$ & 20/07/2013 & Vigente \\
\hline
\end{tabular}

\section{ALMACENES INAR-PG.03}

\begin{tabular}{|c|c|c|c|}
\hline Nº Resolución & Asunto & Vigencia & Estado \\
\hline 1122 / 2001 & Aprobación de la Versión 1 del Procedimiento INAR-PG.03 & $24 / 09 / 2001$ & Vigente \\
\hline $100 / 2004$ & $\begin{array}{l}\text { Modificación del Procedimiento INAR.PG. } 03 \text { Ingreso, Almacenamiento e Inventario de } \\
\text { Mercancias }\end{array}$ & $11 / 03 / 2004$ & Vigente \\
\hline $583 / 2006$ & $\begin{array}{l}\text { Modificación del Procedimiento INAR-PG.03 Ingreso Almacenamiento e Inventario de } \\
\text { Mercancias }\end{array}$ & $16 / 12 / 2008$ & Vigente \\
\hline
\end{tabular}

ADEUDEOS - LIQUIDACIONES DE COBRANZA IFGRA-PE.08

\begin{tabular}{|c|l|c|c|}
\hline$N^{\circ}$ Resolución & \multicolumn{1}{|c|}{ Asunto } & Vigencia & Estado \\
\hline $\mathbf{0 5 8 1 / 2 0 0 3}$ & Aprobación de Procedimiento Adeudos- Liquidaciones de Cobranza & $05 / 01 / 2004$ & Derogado \\
\hline $\mathbf{0 2 7 9 / 2 0 1 2}$ & $\begin{array}{l}\text { Art. 3 - Deja sin efecto el Procedimiento Especifico "ADEUDOS-LIQUIDACIONES DE } \\
\text { COBRANZA", versión 1. }\end{array}$ & $01 / 06 / 2012$ \\
\hline
\end{tabular}

\section{CHEQUES DEVUELTOS IFGRA-PE.09}

\begin{tabular}{|c|l|c|c|}
\hline$N^{\circ}$ Resolución & \multicolumn{1}{|c|}{ Asunto } & Vigencia & Estado \\
\hline $\mathbf{0 2 3 3} / \mathbf{1 9 9 9}$ & $\begin{array}{l}\text { Aprueban Procedimiento Especifico “Cheques Devueltos" recodificado con RSNAA } \\
N^{\circ} \text { RSNAA N 000475-2003/SUNAT/A del 23- oct-2003 }\end{array}$ & $04 / 10 / 1999$ \\
\hline $\mathbf{0 0 5 3 / 2 0 1 0}$ & Art. 2 Deja sin efecto el Procedimiento Especifico « Cheques Devueltos » & $06 / 02 / 2010$ & Vigente \\
\hline
\end{tabular}




\section{AUTOLIQUIDACIÓN DE DEUDA ADUANERA}

INPCFA-PE.03.01

\begin{tabular}{|c|c|c|c|c|}
\hline N" Resolución & \multicolumn{2}{|c|}{ Asunto } & Vigencia & Estado \\
\hline $233 / 1999$ & $\begin{array}{l}\text { Aprobación de Procedimiento Autoliquidación } \\
\text { de Adeudos; } 1 \text { 2003«Adel23-OC1-2003) }\end{array}$ & $\begin{array}{l}\text { INRA-PE.04 (recodificado con RSNAA Nc } \\
\text { 000475- }\end{array}$ & 04.10 .1999 & Derogado \\
\hline $367 / 2003$ & $\begin{array}{l}\text { Aprobación de Procedimiento Especifico } \\
\text { IFGRAPE.11 }\end{array}$ & Autoliquidación de Deuda Aduanera (Versión 2) & 06.082008 & Vigente \\
\hline $0171 / 2013$ & $\begin{array}{l}\text { Aprueba codificación del procedimiento IFGRA- } \\
\text { PE11 }\end{array}$ & $\begin{array}{l}\text { - Como NPCFA-PE } 03.01 \text { "Autoliquidación de } \\
\text { deuda aduanera }\end{array}$ & 20072013 & Vigente \\
\hline
\end{tabular}

\section{FRACCIONAMIENTOS ARANCELARIOS IFGRA-PE.12}

\begin{tabular}{|c|l|c|c|}
\hline $\mathrm{N}^{*}$ Resolución & \multicolumn{1}{|c|}{ Asunto } & Vigencia & Estado \\
\hline $\mathbf{0 0 4 0} / \mathbf{2 0 0 0}$ & Modifican y Aprueban versión del Procedimiento INRA-PE05 & $10 / 07 / 2000$ & Vigente \\
\hline $\mathbf{0 0 5 2} / \mathbf{2 0 0 0}$ & $\begin{array}{l}\text { Modifican Procedimiento INRA-PE 05, recodificado posteriormente como IFGRA-PE } \\
12 \text { V3 con RSNAA 000475-2003 DEL 23.10.2003 }\end{array}$ & $27 / 09 / 2000$ & Vigente \\
\hline
\end{tabular}

\section{BUENOS CONTRIBUYENTES INPCFA-PE.03.07}

\begin{tabular}{|c|l|c|c|}
\hline$N^{*}$ Resolución & \multicolumn{1}{|c|}{ Asunto } & Vigencia & Estado \\
\hline $\mathbf{0 2 3 3} / \mathbf{1 9 9 9}$ & Aprueban Procedimiento INRA-PE.07 segunda versión & $04 / 10 / 1999$ & Derogado \\
\hline $\mathbf{0 0 0 7} / \mathbf{2 0 0 1}$ & Modifican Procedimiento INRA-PE 07 «2- Buenos Contribuyentes & $15 / 01 / 2001$ & Derogado \\
\hline $\mathbf{0 0 1 8} / \mathbf{2 0 0 1}$ & $\begin{array}{l}\text { Modifican Procedimiento INRA-PE 07 V2. recodificado después como IFGRA-PE 14 } \\
\text { con RSNAA 000475-2003 del 23 10.2003 }\end{array}$ & $24 / 03 / 2001$ & Derogado \\
\hline $\mathbf{0 1 5 6} / \mathbf{2 0 0 6}$ & Aprueban Procedimiento IFGRA-PE.14 versión 3 & $26 / 03 / 2006$ & Vigente \\
\hline $\mathbf{0 4 9 1 / 2 0 0 6}$ & Modifica Procedimiento IFGRA-PE.14 v3, sustituye anexo 2 - modelo Pagare & $12 / 10 / 2006$ & Vigente \\
\hline $\mathbf{0 1 7 1} / \mathbf{2 0 1 3}$ & $\begin{array}{l}\text { Aprueba codificación del procedimiento IFGRA-PE.14 como INPCFA-PE 03 07 } \\
\text { Buenos Contribuyentes }\end{array}$ & $20 / 07 / 2013$ & Vigente \\
\hline
\end{tabular}


EXTINCIÓN DE DEUDAS POR PAGO INPCFA-PE.02.01

\begin{tabular}{|c|l|c|c|}
\hline$N^{*}$ Resolución & \multicolumn{1}{|c|}{ Asunto } & Vigencia & Estado \\
\hline $\mathbf{5 8 1} / \mathbf{2 0 0 3}$ & Aprueban nueva versión del Procedimiento Pago - Extinción de Adeudos & $05 / 01 / 2004$ & Derogado \\
\hline $\mathbf{0 8 2}$ / 2005 & Actualizan Procedimiento IFGRA-PE.15 “Pago-extinción de Adeudos” & $01 / 03 / 2005$ & Derogado \\
\hline $\mathbf{0 5 3} / \mathbf{2 0 1 0}$ & Aprueban nueva versión del Procedimiento IFGRA-PE.15 “Extinción de Deudas por Pago" & $06 / 02 / 2010$ & Derogado \\
\hline $\mathbf{0 1 7 1} / \mathbf{2 0 1 3}$ & $\begin{array}{l}\text { Aprueban codificación del Procedimiento IFGRA-PE.15 como INPCFA-PE 02.01 Extinción de } \\
\text { Deudas por Pago }\end{array}$ & $\mathbf{2 0 / 0 7 / 2 0 1 3}$ & Vigente \\
\hline
\end{tabular}

\section{DOCUMENTOS VALORADOS} INPCFA-PE.02.02

\begin{tabular}{|c|c|c|c|}
\hline$N^{\circ}$ Resolución & Asunto & Vigencia & Estado \\
\hline $0233 / 1999$ & $\begin{array}{l}\text { Aprueban Procedimiento Especio "Documentos valorados" (recodificado con RSNAA IT 000475- } \\
\text { 2003/SUNAT/A del 23-Ocí-2003) }\end{array}$ & $04 / 10 / 2011$ & Vigente \\
\hline $0171 / 2013$ & $\begin{array}{l}\text { Aprueba codificación del procedimiento IFGRA-PE.16 como INPCFA-PE.02 } 02 \text { DOCUMENTOS } \\
\text { VALORADOS }\end{array}$ & $20 / 0 \mathrm{~J} / 2013$ & Vigente \\
\hline
\end{tabular}

\section{DEVOLUCIÓN DE PAGOS AL AMPARO DEL D.S. 15-94-EF DEPOSITADOS EN LAS CUENTAS DEFINITIVAS DEL TESORO PÚBLICO INPCFA-PE.05.02}

\begin{tabular}{|c|l|c|c|}
\hline$N^{\circ}$ Resolución & \multicolumn{1}{|c|}{ Asunto } & Vigencia & Estado \\
\hline $\mathbf{0 2 3 3}$ / 1999 & $\begin{array}{l}\text { Aprueban Procedimiento INRA-PE 11 VERSIÓN 2 recodificación como IFGRA-PE 18 V2 con } \\
\text { RSNNA N 000475-2003/SUNAT/A DEL 23.10.2003 }\end{array}$ & 04/10/1999 & Vigente \\
\hline $\mathbf{0 1 7 1}$ / $\mathbf{2 0 1 3}$ & $\begin{array}{l}\text { Aprueba codificación del procedimiento IFGRA-PE.18 como INPCFA-PE.02 Devolución de Pagos } \\
\text { al Amparo del D.S. 15-94-EF depositados en las cuentas de Tesoro Publico }\end{array}$ & $20 / 07 / 2013$ & Vigente \\
\hline
\end{tabular}




\section{GARANTÍAS DE OPERADORES DE COMERCIO EXTERIOR}

INPCFA-PE.03.04

\begin{tabular}{|c|c|c|c|}
\hline Nº Resolución & Asunto & Vigencia & Estado \\
\hline $0233 / 1999$ & Aprueban Procedimiento INRA-PE.13 v2 Garantías de Subcontratistas & 04/10/1999 & Derogado \\
\hline $0041 / 2000$ & $\begin{array}{l}\text { Modifican Procedimiento INRA-PE.13 "Garantías de Subcontratistas". recodificado } \\
\text { posteriormente como IFGRA-PE.20 con RSNAA N }{ }^{\circ} 000475-2003 \text { / SUNAT/A del 23.10.2003 }\end{array}$ & $10 / 07 / 2000$ & Derogado \\
\hline $0493 / 2005$ & Aprueban Procedimiento IFGRA-PE.20 "Garantías de Operadores de Comercio Exterior v3 & $24 / 10 / 2005$ & Vigente \\
\hline $00012 / 2013$ & $\begin{array}{l}\text { Modifican Anexo } 1 \text { referente a Modelo de Carta Fianza o Póliza de Caución del } \\
\text { Procedimiento IFGRA-PE.20 "Garantías de Operadores de Comercio Exterior" v3 }\end{array}$ & $21 / 01 / 2013$ & Vigente \\
\hline $0171 / 2013$ & $\begin{array}{l}\text { Aprueba codificación del procedimiento IFGRA-PE.20 como INPCFA-PE.03.04 Garantías de } \\
\text { Operadores de Comercio Exterior }\end{array}$ & $20 / 07 / 2013$ & Vigente \\
\hline
\end{tabular}

\section{ADMISIÓN TEMPORAL PARA REEXPORTACIÓN EN EL MISMO ESTADO INTA PG-04}

\begin{tabular}{|c|c|c|c|}
\hline$N^{\circ}$ Resolución & Asunto & Vigencia & Estado \\
\hline $2170 / 1999$ & Modificación según Resolución 2170 & $07 / 01 / 2000$ & Derogado \\
\hline 1972 / 2000 & Modificación según Resolución 1972 & $17 / 07 / 2000$ & Derogado \\
\hline 0464 / 2001 & Modificación según Resolución 0464 & 04/03/2001 & Derogado \\
\hline $0596 / 2005$ & $\begin{array}{l}\text { Aprueba versión } 3 \text { Procedimiento de Importación Temporal para Reexportación } \\
\text { en el mismo Estado }\end{array}$ & $20 / 12 / 2005$ & Derogado \\
\hline $0153 / 2009$ & $\begin{array}{l}\text { Aprueban versión } 4 \text { del Procedimiento INTA-PG.04 - Admisión Temporal para } \\
\text { Reexportación en el Mismo Estado }\end{array}$ & $22 / 03 / 2009$ & Derogado \\
\hline $062 / 2010$ & $\begin{array}{l}\text { Aprueban versión } 5 \text { del Procedimiento INTA-PG.04 • Admisión Temporal para } \\
\text { Reexportación en el Mismo Estado }\end{array}$ & $\begin{array}{l}\text { 22.02.2010 lío y Paita. } 08.03 \\
2010 \text { Chimbote. Mollendo. Pisco } \\
\text { y Salaverry } 30.09 .2010 \text { para } \\
\text { Arequipa Chiclayo. Cusco. } \\
\text { Iquitos. Postal Callao. Pucallpa } \\
\text { Puerto Matado. Puno. Tacna. } \\
\text { Tarapoto. Tumbes. Agencia } \\
\text { Aduanera la Tina. Marítima } \\
\text { Callao v Aérea Callao }\end{array}$ & Vigente \\
\hline $117 / 2011$ & $\begin{array}{l}\text { Modifican el Procedimiento General "ADMISION TEMPORAL PARA } \\
\text { REEXPORTACION EN EL MISMO ESTADO' INTA-PG.04 (versión 5) }\end{array}$ & $31 / 03 / 2011$ & Vigente \\
\hline
\end{tabular}

\begin{tabular}{|c|c|c|c|}
\hline \multicolumn{3}{|c|}{ EXPORTACIÓN TEMPORAL PARA REIMPORTACIÓN EN EL MISMO ESTADO } \\
INTA PG-05
\end{tabular}


ERRORES EN LA FACTURA COMERCIAL

INTA PE-00.01

\begin{tabular}{|c|r|c|c|}
\hline$N^{\circ}$ Resolución & Asunto & Vigencia & Estado \\
\hline $\mathbf{0 5 2 5} / \mathbf{2 0 0 3}$ & Aprueban Versión 2 del INTA-PE00.01 & $09 / 12 / 2003$ & Vigente \\
\hline
\end{tabular}

TELEDESPACHO

INTA PE-00.02

\begin{tabular}{|c|c|c|c|}
\hline$N^{\circ}$ Resolución & Asunto & Vigencia & Estado \\
\hline $0525 / 2003$ & Aprueban Versión 2 del INTA-PE 00.02 & 09.12 .2003 & Derogado \\
\hline $0181 / 2005$ & Aprueban modificación del INTA-PE 00.02 & 14.04.2005 & Derogado \\
\hline $614 / 2008$ & Aprueban versión 3 del INTA-PE 00.02 & $\begin{array}{l}\text { 22.02.2010 lío y Paita. } 08.032010 \\
\text { Chimbote. Mollendo. Pisco y Salaverry } \\
\text { 30.09.2010 para Arequipa Chiclayo. } \\
\text { Cusco. Iquitos. Postal Callao. Pucallpa } \\
\text { Puerto Matado. Puno. Tacna. Tarapoto. } \\
\text { Tumbes. Agencia Aduanera la Tina. } \\
\text { Marítima Callao v Aérea Callao }\end{array}$ & Vigente \\
\hline $583 / 2010$ & Modifican numeral 9 de la sección VI del P.E. INTA-PE 00.02 V.3 & 03/10/2010 & Vigente \\
\hline
\end{tabular}

AUTORIZACIÓN Y ACREDITACIÓN DE OPERADORES DE COMERCIO EXTERIOR INTA PG-24

\begin{tabular}{|c|c|c|c|}
\hline $\mathbf{N}^{*}$ Resolución & Asunto & Vigencia & Estado \\
\hline $0581 / 2005$ & $\begin{array}{l}\text { Aprueban procedimiento Autorización y Acreditación de Operadores de Comercio Exterior INTA- } \\
\text { PG.24 }\end{array}$ & $16 / 01 / 2006$ & Derogado \\
\hline $0227 / 2006$ & $\begin{array}{l}\text { Aprueban modificación al procedimiento INTA-PG.24 Autorización y Acreditación de } \\
\text { Operadores de Comercio Exterior }\end{array}$ & $27 / 04 / 2006$ & Derogado \\
\hline $0236 / 2008$ & $\begin{array}{l}\text { Aprueban Versión } 2 \text { del Procedimiento INTA-PG.24 Autorización y Acreditación de Operadores } \\
\text { de Comercio Exterior. }\end{array}$ & $04 / 05 / 2006$ & Vigente \\
\hline 0522 / 2008 & $\begin{array}{l}\text { Modifican RSNAA N" 236-2008 SUNATA que aprobó el Procedimiento "Autorización v } \\
\text { Acreditación de Operadores de Comercio Exterior INTA-PG } 24 \text { (versión 2) }\end{array}$ & $04 / 11 / 2008$ & Vigente \\
\hline $0462 / 2009$ & Modifican procedimiento INTA-PG 24 V.2 & $16 / 09 / 2009$ & Vigente \\
\hline 494 / 2011 & $\begin{array}{l}\text { Artículo 3a - Dejar sin efecto el inciso i), numeral 4, literal E 2, sección VII del procedimiento } \\
\text { "Autorización y Acreditación de Operadores de Comercio Exterior" INTA-PG.24 (versión 2) } \\
\text { aprobado por Resolución de Superintendencia Nacional Adjunta de Aduanas N* 236- } \\
\text { 2008/SUNAT/A. }\end{array}$ & $30 / 12 / 2011$ & Vigente \\
\hline $539 / 2012$ & $\begin{array}{l}\text { Modifican el Procedimiento General "Autorización y Acreditación de Operadores de Comercio } \\
\text { Exterior INTA-PG.24 (versión 2) }\end{array}$ & $20 / 12 / 2012$ & vigente \\
\hline $145 / 2013$ & $\begin{array}{l}\text { Modifican el Procedimiento General 'Autorización y Acreditación de Operadores de Comercio } \\
\text { Exterior INTA-PG.24 (versión 2) }\end{array}$ & $19 / 06 / 2013$ & Vigente \\
\hline $396 / 2013$ & $\begin{array}{l}\text { Modifican el Procedimiento General "Autorización y Acreditación de Operadores de Comercio } \\
\text { Exterior INTA-PG.24 (versión 2) }\end{array}$ & $19 / 12 / 2013$ & Vigente \\
\hline $410 / 2013$ & $\begin{array}{l}\text { Modifican el Procedimiento General "Autorización y Acreditación de Operadores de Comercio } \\
\text { Exterior INTA-PG.24 (versión 2) }\end{array}$ & $31 / 12 / 2013$ & Vigente \\
\hline $019 / 2014$ & $\begin{array}{l}\text { Modifican el Procedimiento General 'Autorización y Acreditación de Operadores de Comercio } \\
\text { Exterior INTA-PG.24 (versión 2) }\end{array}$ & $19 / 12 / 2014$ & Vigente \\
\hline $006 / 2015$ & $\begin{array}{l}\text { Modifican el Procedimiento General "Autorización y Acreditación de Operadores de Comercio } \\
\text { Exterior INTA-PG } 24 \text { versión } 2\end{array}$ & $01 / 04 / 2015$ & Vigente \\
\hline $007 / 2015$ & $\begin{array}{l}\text { Modifican el Procedimiento General "Autorización y Acreditación de Operadores de Comercio } \\
\text { Exterior INTA-PG } 24 \text { versión 2) }\end{array}$ & $15 / 04 / 2015$ & Vigente \\
\hline 012 / 2015 & $\begin{array}{l}\text { Modifican el Procedimiento General "Autorización y Acreditación de Operadores de Comercio } \\
\text { Exterior" INTA-PG } 24 \text { (versión 2) }\end{array}$ & $20 / 06 / 2015$ & Vigente \\
\hline
\end{tabular}




\section{DONACIONES}

\section{INTAPE-01.02}

\begin{tabular}{|c|c|c|c|}
\hline$N^{\circ}$ Resolución & Asunto & Vigencia & Estado \\
\hline $1780 / 1999$ & Según Resolución 1780 & 05/12/1999 & No vigente \\
\hline $1608 / 2000$ & Según Resolución 1608 & $12 / 06 / 2000$ & $\begin{array}{c}\text { Vigente excepto el } \\
\text { Articulo } 1\end{array}$ \\
\hline $2248 / 2000$ & Según Resolución 2248 & $11 / 08 / 2000$ & No Vigente \\
\hline 1118 / 2001 & Según Resolución 1118 & 01/06/2001 & No Vigente \\
\hline $1294 / 2002$ & Según Resolución 1294 & $16 / 07 / 2002$ & No Vigente \\
\hline 1382 / 2002 & Según Resolución 1382 & 03/08/2002 & No Vigente \\
\hline $009 / 2013$ & $\begin{array}{l}\text { Aprueban Procedimiento Especifico "Donaciones Provenientes del Exterior “ INTA-PE } 01.02 \\
\text { (versión 2) }\end{array}$ & $14 / 09 / 2013$ & Vigente \\
\hline
\end{tabular}

BENEFICIOS TRIBUTARIOS: SECTOR AGRARIO Y DISCAPACITADOS INTA PE-01.03

\begin{tabular}{|c|l|c|c|}
\hline$N^{\circ}$ Resolución & \multicolumn{1}{|c|}{ Asunto } & Vigencia & Estado \\
\hline $\mathbf{1 6 0 8} / \mathbf{2 0 0 0}$ & Según Resolución 01608 Beneficio Tributarios Sector Agrario y Discapacitado & 12.06 .2000 & Vigente \\
\hline $\mathbf{1 8 8 6} / \mathbf{2 0 0 1}$ & Según Resolución 01886 Beneficio Tributarios Sector Agrario y Discapacitado & 12.08 .2000 & Vigente \\
\hline $\mathbf{2 4 7 5} / \mathbf{2 0 0 1}$ & Según Resolución 02475 Beneficio Tributarios Sector Agrario y Discapacitado & 10.11 .2001 & Vigente \\
\hline
\end{tabular}

\section{RECTIFICACIÓN DE LA DECLARACIÓN INTA PE-01.07}

\begin{tabular}{|c|c|c|c|}
\hline$N^{\circ}$ Resolución & Asunto & Vigencia & Estado \\
\hline $1956 / 2000$ & Modificación según Resolución 1956 -2000 del INTA-PE.01.07 & $17 / 07 / 2000$ & Derogado \\
\hline $0524 / 2003$ & Según Resolución 00524 se aprueba versión 2 del INTA-PE.01.07 & 09/12/2003 & Derogado \\
\hline $0154 / 2005$ & $\begin{array}{l}\text { Aprueba versión } 3 \text { 'Procedimiento de Solicitud Electrónica de } \\
\text { Rectificación de la Declaración Única de Aduanas" }\end{array}$ & $12 / 05 / 2005$ & $\begin{array}{l}\text { Derogado por RSNAA } \\
\text { 03/2010 que aprueba } \\
\text { INTA- PE.00.11íV.1) }\end{array}$ \\
\hline $0629 / 2007$ & Aprueban modificación de procedimiento INTA-PE.01.07 & $10 / 11 / 2007$ & Derogado \\
\hline $504 / 2010$ & $\begin{array}{l}\text { Aprueba versión } 4 \text { 'Procedimiento de Solicitud Electrónica de } \\
\text { Rectificación de la Declaración Única de Aduanas" }\end{array}$ & $\begin{array}{c}\text { 01/09/2010 para } \\
\text { Arequipa. Chiclayo. } \\
\text { Cusco, (quitos. Pucallpa } \\
\text { Puerto Maldonado. Puno } \\
\text { Tacna Tarapoto Tumbes } \\
\text { Agenda Aduanera la Tina } \\
\text { el 22/09/2010 para } \\
\text { Marítima del Callao el } \\
\text { 27/09/2010 para la Aérea } \\
\text { del Callao y el } \\
\text { 30/09/2010 para Postal } \\
\text { Callao }\end{array}$ & Vigente \\
\hline $11 / 2013$ & $\begin{array}{l}\text { Modifican Procedimiento Especifico “Solicitud Electrónica de } \\
\text { Rectificación de la Declaración Única de Aduanas' ¡NTA-PE.0107 }\end{array}$ & $11 / 10 / 2013$ & Vigente \\
\hline $09 / 2014$ & $\begin{array}{l}\text { Excluyen a la IAMC del Procedimiento Específico "Solicitud Electrónica } \\
\text { de Rectificación de la Declaración Única de Aduanas" INTA-PE.01.07 }\end{array}$ & $12 / 01 / 2015$ & Vigente \\
\hline
\end{tabular}




\section{SOLICITUD DE RECTIFICACIÓN ELECTRÓNICA DE DECLARACIÓN}

INTA PE-00.11

\begin{tabular}{|c|c|c|c|}
\hline$N^{\circ}$ Resolución & Asunto & Vigencia & Estado \\
\hline $0003 / 2010$ & $\begin{array}{l}\text { Aprueba Versión } 1 \text { del Procedimiento Especifico "Solicitud de Rectificación Electrónica } \\
\text { de Declaración" INTA-PE0fl.11 }\end{array}$ & 22/02/2010 & No Vigente \\
\hline $0043 / 2010$ & $\begin{array}{l}\text { Modifican versión } 1 \text { del Procedimiento Específico "Solicitud de Rectificación Electrónica } \\
\text { de Declaración" INTA-PE.00.11 }\end{array}$ & 22/02/2010 & No Vigente \\
\hline $0504 / 2010$ & $\begin{array}{l}\text { Modifican versión } 1 \text { del Procedimiento Específico "Solicitud de Rectificación Electrónica } \\
\text { de Declaración" INTA-PE00.11 }\end{array}$ & $01 / 092010$ & No Vigente \\
\hline $09 / 2014$ & $\begin{array}{l}\text { Aprueba Versión } 2 \text { del Procedimiento Específico "Solicitud de Rectificación Electrónica } \\
\text { de Declaración" INTA-PE.00.11 }\end{array}$ & $\begin{array}{c}\text { Artículo 4V La presente } \\
\text { resolución entrará en } \\
\text { vigencia a partir del } 06 \\
\text { de octubre de } 2014 . \\
\text { Excepto para la } \\
\text { Intendencia de Aduana } \\
\text { Marítima del Callao y lo } \\
\text { dispuesto en el artículo } \\
\text { 3' precedente, cuya } \\
\text { vigencia será a partir } \\
\text { del } 12 \text { de enero de } \\
2015 .\end{array}$ & Vigente \\
\hline $01 / 2015$ & Prorrogan la entrada en vigencia del ciertas Resoluciones de Intendencia Nacional & $12 / 01 / 2015$ & Vigente \\
\hline $08 / 2015$ & $\begin{array}{l}\text { Precisan las fechas de entrada en vigencia en la Intendencia de Aduana Marítima del } \\
\text { Callao de diversas Resoluciones de Intendencia Nacional según las modalidades de } \\
\text { despacho. }\end{array}$ & $18 / 04 / 2010$ & Vigente \\
\hline
\end{tabular}

APLICACIÓN DE RESOLUCIONES LIBERATORIAS

INTA PE-01.09

\begin{tabular}{|c|l|c|c|}
\hline$N^{\circ}$ Resolución & Asunto & Vigencia & Estado \\
\hline $\mathbf{0 5 4 0} / \mathbf{2 0 0 3}$ & Aprueba Versori 2 • Resoluciones Liberatorias & $11 / 12 / 2003$ & Vigente \\
\hline $\mathbf{6 0 4} / \mathbf{2 0 1 0}$ & Modificación del INTA-PE 01.09 & $15 / 11 / 2010$ & Vigente \\
\hline
\end{tabular}

VALORACIÓN DE MERCANCÍAS

INTA PE-01.10

\begin{tabular}{|c|l|c|c|}
\hline$N^{\circ}$ Resolución & \multicolumn{1}{|c|}{ Asunto } & Vigencia & Estado \\
\hline $1059 / 1999$ & Modificación ssegún Resolución 1059 & $20 / 09 / 1999$ & Vigente \\
\hline $\mathbf{0 2 2 6} / \mathbf{2 0 0 0}$ & Modiiicacion según Resolución 0226 & $30 / 01 / 2001$ & Vigente \\
\hline $1545 / 2000$ & Modificación según Resolución 1545 & $07 / 06 / 2000$ & Vigente \\
\hline
\end{tabular}

APLICACIÓN PREFERENCIAS A LA IMPORTACIÓN DE MERCANCÍAS EN ALADI

\begin{tabular}{|c|l|c|c|}
\hline$N^{\circ}$ Resolución & \multicolumn{1}{|c|}{ Asunto } & Vigencia & Estado \\
\hline $\mathbf{0 1 5} / \mathbf{2 0 1 3}$ & Aprueban version 3 del Procedimiento INTA-PE 01.12 & $29 / 12 / 2013$ & Derogado \\
\hline RIN $\mathbf{0 1 5} / \mathbf{2 0 1 3}$ & Se aprueba la tercera version del Procedimiento INTA-PE.01.12-V3.doc & Vigente \\
\hline
\end{tabular}

\section{CONTROL DE MERCANCÍAS RESTRINGIDAS Y PROHIBIDAS} INTA PE-00.06

\begin{tabular}{|c|l|c|c|}
\hline$N^{\circ}$ Resolución & \multicolumn{1}{|c|}{ Asunto } & Vigencia & Estado \\
\hline $\mathbf{0 1 2 4} / \mathbf{2 0 0 0}$ & Resolución 0124 - Control de Mercancías Restringidas & $21 / 01 / 2000$ & Derogado \\
\hline $\mathbf{0 3 3 2} / \mathbf{2 0 0 4}$ & $\begin{array}{l}\text { Aprobación de la versión 2 del Procedimiento de Mercancias Restringidas y Prohibidas } \\
\text { INTA-PE 00.06 }\end{array}$ & $23 / 07 / 2004$ \\
\hline
\end{tabular}




\section{BENEFICIO TRIBUTARIOS: EDUCACIÓN INTA PE-01.05}

\begin{tabular}{|c|l|c|c|}
\hline$N^{\circ}$ Resolución & Asunto & Vigencia & Estado \\
\hline $1608 / 2000$ & Resolución 01608 Beneficio Tributario: Educación & $12 / 06 / 2000$ & Vigente \\
\hline $\begin{array}{c}\text { M.E. 153-2013- } \\
\text { División de Proceso } \\
\text { de Ingreso }\end{array}$ & Actualización de la Correlación del Arancel & $01 / 01 / 2012$ \\
\hline $\begin{array}{c}\text { Ley No 30220 “Ley } \\
\text { Universitaria" }\end{array}$ & Modificación del Anexo II & Vigente & $09 / 07 / 2014$ \\
\hline
\end{tabular}

\section{APLICACIÓN DE TRIBUTOS, DERECHOS ANTIDUMPING Y COMPENSATORIOS} INTA PE-01.08

\begin{tabular}{|c|l|c|c|}
\hline$N^{\circ}$ Resolución & \multicolumn{1}{|c|}{ Asunto } & Vigencia & Estado \\
\hline $0001 / 2000$ & Modificación segun Resolución 0001 & 07012000 & Vigente \\
\hline
\end{tabular}

\section{CLASIFICACIÓN ARANCELARIA DE MERCANCIÁS INTA PE-00.09}

\begin{tabular}{|c|l|c|c|}
\hline$N^{\circ}$ Resolución & \multicolumn{1}{|c|}{ Asunto } & Vigencia & Estado \\
\hline $\mathbf{1 2 7 1} / \mathbf{2 0 0 0}$ & Aprueba procedimiento de Clasificación Arancelarias de mercancías & $14 / 05 / 2000$ & Derogado \\
\hline $\mathbf{0 8 3 2} / \mathbf{2 0 0 2}$ & Modificación según Resolución & $13 / 05 / 2002$ & Derogado \\
\hline $\mathbf{0 6 2 7} / \mathbf{2 0 0 7}$ & Aprueba Versión 2 de procedimiento de Clasificación Arancelaras de mercancías & $22 / 11 / 2007$ & Derogado \\
\hline $\mathbf{0 5 0 7} / \mathbf{2 0 1 2}$ & Aprueba Versión 3 de procedimiento de Clasificación Arancelarias de mercancias & $17 / 11 / 2012$ & Vigente \\
\hline
\end{tabular}

INMOVILIZACIÓN - INCAUTACIÓN Y DETERMINACIÓN LEGAL DE MERCANCÍAS

\begin{tabular}{|c|c|c|c|}
\hline N Resolución & Asunto & Vigencia & Estado \\
\hline $1021 / 2000$ & Aprobación del procedimiento INFA-PE05 V2 & $17 / 07 / 2000$ & Derogado \\
\hline $0713 / 2001$ & Aprobación del procedimiento INPC-PE02 V1 & $18 / 06 / 2001$ & Derogado \\
\hline $0068 / 2001$ & Aprobación del procedimiento INPC.PE02 V2 & 07/01/2002 & Derogado \\
\hline $0302 / 2002$ & Aprobación del procedimiento IPCF.PE02 V3 & $01 / 01 / 2003$ & Derogado \\
\hline $0267 / 2006$ & Rectificación del procedimiento ipcf.pe02 a ipcf-pe 00.01 & $18 / 05 / 2006$ & Vigente \\
\hline $0315 / 2006$ & Aprobación del procedimiento IPCF.PE00.01 V4 & $16 / 06 / 2006$ & Derogado \\
\hline $0530 / 2012$ & Aprobación del procedimiento IPCF.PE00.01 V5 & $05 / 12 / 2012$ & Derogado \\
\hline $0171 / 2013$ & $\begin{array}{l}\text { Aprueban codificación de los procedimientos ipcf.pe.00.01 como inpcfa.pe.00.01 e ipcf- } \\
\text { pe.00.02 }\end{array}$ & $20 / 07 / 2013$ & Vigente \\
\hline $0226 / 2013$ & Aprueban procedimiento inpcfa-pe.00.01 v6 & $13 / 09 / 2013$ & Vigente \\
\hline
\end{tabular}




\section{CONFECCIÓN, LLENADO Y REGISTRO DEL ACTA DE INMOVILIZACIÓN-INCAUTACIÓN} IPCF-IT.00.01.01

\begin{tabular}{|c|l|c|c|}
\hline$N^{\circ}$ Resolución & \multicolumn{1}{|c|}{ Asunto } & Vigencia & Estado \\
\hline $1021 / 2000$ & $\begin{array}{l}\text { Aprueba v2 procedimiento INFA-IT.01 "Llenado del acta de Inmovilización - } \\
\text { incautación -Comiso" }\end{array}$ & $17 / 07 / 2000$ & Derogado \\
\hline 0044 / 2001 & Aprueba vi procedimiento ÍNFA-IT.03 "Uso del Módulo INFA-PE.05" & $16 / 02 / 2001$ & Derogado \\
\hline $0713 / 2001$ & $\begin{array}{l}\text { Aprueba vi procedimiento INPC-IT.01 "Llenado y registro del "acta de inmovilización- } \\
\text { Inmovilización - incautación " }\end{array}$ & $18 / 06 / 2001$ & Derogado \\
\hline $0302 / 2003$ & $\begin{array}{l}\text { Aprueba v2 procedimiento IPCF-IT.01 'Llenado del acta de Inmovilización - } \\
\text { incautación -Comiso' }\end{array}$ & $01 / 01 / 2003$ & Derogado \\
\hline $0267 / 2006$ & Recodifica procedimiento 1PCF-IT01 por código IPCF-IT.00 0101 & $18 / 15 / 2006$ & Derogado \\
\hline $573 / 2008$ & $\begin{array}{l}\text { Aprueban Instructivo de Confección. Llenado v Registro del Acta de Inmovilización - } \\
\text { incautación }\end{array}$ & $23 / 01 / 2009$ & Vigente \\
\hline
\end{tabular}

\section{INSPECCIÓN DE MERCANCÍAS EN ZONA PRIMARIA INPCFA PE.01.03}

\begin{tabular}{|c|l|c|c|}
\hline$N^{\circ}$ Resolución & \multicolumn{1}{|c|}{ Asunto } & Vigencia & Estado \\
\hline $\mathbf{0 6 2 3}$ / $\mathbf{2 0 0 0}$ & Aprobación con RIN 0623 de la versión 3 del INFA-PE.04 & $10 / 07 / 2000$ & Derogado \\
\hline $\mathbf{0 4 7 5}$ / $\mathbf{2 0 0 3}$ & Recodificación del INFA.PE.04 inmovilización e inspección de carga en zona primaria & $27 / 10 / 2003$ & Derogado \\
\hline $\mathbf{0 5 8 1}$ / $\mathbf{2 0 0 3}$ & Aprobación versión 1 FRGA-PE.05 inmovilización e inspección de carga en zona primaria & $05 / 01 / 2004$ & Derogado \\
\hline $\mathbf{0 0 1 7 1}$ / $\mathbf{2 0 1 3}$ & $\begin{array}{l}\text { Codificación del INPCFA-PE.01.03 inmovilización e inspección de carga en zona primaria (ex } \\
\text { ifgra-pe05) }\end{array}$ & $20 / 07 / 2013$ & Vigente \\
\hline $\mathbf{0 0 2 0 8}$ / $\mathbf{2 0 1 3}$ & $\begin{array}{l}\text { Aprueban versión 2 del procedimiento INPCFA-PE 01.03 "inspección de mercancías en zona } \\
\text { primaria }\end{array}$ & $27 / 08 / 2013$ & Vigente \\
\hline $\mathbf{0 2 2 6}$ / $\mathbf{2 0 1 3}$ & $\begin{array}{l}\text { Modifica el inciso b) del numeral 3) del rubro viia3 del procedimiento especifico "inspección de } \\
\text { mercancías en zona primaria" INPCFA-PE 01.03 (versión 2) }\end{array}$ & $13 / 09 / 2013$ & Vigente \\
\hline
\end{tabular}

\section{VISITAS DE INSPECCIÓN A DESPACHADORES DE ADUANA IFGRA PE.03}

\begin{tabular}{|c|l|c|c|}
\hline \multirow{2}{*}{$N^{\circ}$ Resolución } & \multicolumn{1}{|c|}{ Asunto } & Vigencia & \multicolumn{1}{|c|}{ Estado } \\
\hline $\mathbf{0 6 2 8} / \mathbf{2 0 0 0}$ & $\begin{array}{l}\text { Aprobación con RIN del procedimiento INFA-PE01 Visitas de auditoria a despachadores de } \\
\text { aduana versión 2 }\end{array}$ & $10 / 07 / 2000$ & Derogado \\
\hline $\mathbf{0 4 7 5} / \mathbf{2 0 0 3}$ & Recodificación del INFA-PE01 Visitas de inspección a despachadores de aduana-ifgra-pe.03 & $27 / 10 / 2003$ & Derogado \\
\hline $\mathbf{0 1 9 3} / 2012$ & $\begin{array}{l}\text { Deja sin efecto el procedimiento IFGRA-PE03 "Visitas de inspección a despachadores de } \\
\text { aduana" }\end{array}$ & $25 / 04 / 2012$ & Vigente \\
\hline
\end{tabular}




\section{DEPÓSITO ADUANERO}

INTA PG-03

\begin{tabular}{|c|l|c|c|}
\hline$N^{\circ}$ Resolución & Asunto & Vigencia & Estado \\
\hline $\mathbf{0 1 4 5}$ / 2009 & Aprueban versión 4 del procedimiento INTA-PG.03 - Deposito Aduanero & $04 / 09 / 2004$ & Derogado \\
\hline $\mathbf{0 4 4 7}$ / 2009 & Dejan en suspenso disposiciones del Procedimiento Aduanero INTA-PG.03 (V4) & $04 / 09 / 2009$ & Vigente \\
\hline $\mathbf{0 6 4}$ / 2010 & Aprueban versión 5 del Procedimiento INTA-PG.03 (V5) Deposito Aduanero & $\begin{array}{c}\text { Paita y 08/03/2010 para } \\
\text { Chimbote, Mollendo, } \\
\text { Pisco y Salvarry }\end{array}$ & Vigente \\
\hline
\end{tabular}

\section{ADJUDICACIÓN DE MERCANCÍAS \\ INA-PG.15}

\begin{tabular}{|c|l|c|c|}
\hline$N^{\circ}$ Resolución & \multicolumn{1}{|c|}{ Asunto } & \multicolumn{1}{c|}{ Vigencia } & Estado \\
\hline $\mathbf{0 3 3 5}$ / 2003 & Aprobación de la versión 1 del Procedimiento INA-PG.15 & $03 / 08 / 2003$ & Derogado \\
\hline $\mathbf{0 4 5 4}$ / 2003 & Aprobación de la versión 2 del Procedimiento INA-PG.15 V2 & $17 / 10 / 2003$ & Derogado \\
\hline $\mathbf{0 4 7 8} / \mathbf{2 0 0 4}$ & Meditación del Procedimiento INA-PG.15 V2 Adjudicación de Mercancías & $15 / 10 / 2004$ & Derogado \\
\hline $\mathbf{0 6 0 4} / \mathbf{2 0 0 4}$ & Mitón del Procedimiento INA-PG.15 V2 Adjudicación de Mercancías & $03 / 01 / 2005$ & Derogado \\
\hline $\mathbf{0 2 9 1} / \mathbf{2 0 0 6}$ & Modificación del Procedimiento INA-PG.15 V2 Adjudicación de Mercancías & $25 / 05 / 2006$ & Derogado \\
\hline $\mathbf{0 2 9 9} / \mathbf{2 0 0 9}$ & Medicación del Procedimiento INA-PG.15 V2 Adjudicación de Mercancías & $15 / 06 / 2006$ & Derogado \\
\hline $\mathbf{0 3 4 7} / \mathbf{2 0 1 1}$ & Aprobación del Procedimiento INA-PG.15 V3 Adjudicación de Mercancías & $24 / 09 / 2011$ & Vigente \\
\hline
\end{tabular}




\section{RECONOCIMIENTO FÍSICO EXTRACIÓN Y ANÁLISIS DE MUESTRAS INTA PE-00.03}

\begin{tabular}{|c|c|c|c|}
\hline$N^{\circ}$ Resolución & Asunto & Vigencia & Estado \\
\hline $1059 / 1999$ & Aprueba versión I del Procedimiento (MTA-PE00.03 & 27/01/1999 & Derogado \\
\hline $1673 / 1999$ & Según Resolución 1673 modifica Proc. INTA-PE.üü.03 & 28/11/1959 & Derogado \\
\hline $2061 / 1999$ & Según Resolución 2061modifica Procedimiento tNTA-PE.00.03 & 27/12/1999 & Derogado \\
\hline $0202 / 2001$ & Aprueba versión 2 del Proc. INTA-PE.00,03 con Res 0202 /2001 & $01 / 02 / 2001$ & Derogado \\
\hline $0806 / 2002$ & Modifica el Proc. INTA-PE.00.03 con Res 0806 / 2002 & $28 / 04 / 2002$ & Derogado \\
\hline $0416 / 2009$ & Modifican procedimiento INTA-PE00.03 & $21 / 08 / 2009$ & Derogado \\
\hline $0061 / 2010$ & Aprueban versión 3. Procedimiento Específico INTA-PE.00.03 & 01/06/2010 & Vigente \\
\hline $0335 / 2010$ & Modifican Procedimiento Especifico íNTA-PE.00.03 & $01 / 06 / 2010$ & Vigente \\
\hline 012 / 2014 & Modifican Procedimiento Especifico INTA-PE.00.03 (V3) & 18/04/2015 & Vigente \\
\hline $01 / 2015$ & Prorrogan la entrada en vigencia del ciertas Resoluciones de Intendencia Nacional & $12 / 01 / 2015$ & Vigente \\
\hline $08 / 2015$ & $\begin{array}{l}\text { Precisan las lechas de entrada en vigencia en la Intendencia de Aduana Marine del Callao de } \\
\text { diversas Resoluciones de Intendencia Nacional según las modalidades de despacho. }\end{array}$ & $18 / 04 / 2015$ & Vigente \\
\hline $10 / 2015$ & Modifican Procedimiento Específico INTA-PE.00.03-Numeral 1, literal B. sección Vil & $30 / 06 / 2015$ & Vigente \\
\hline
\end{tabular}

Otros Procedimientos Específicos:

Recepción y Devolución de Garantías en efectivo / Artículo 13 del Acuerdo de la OMC R.S.N.A 00581 / 2003 (Vig.05.01.2004) IFGRA-PE.21

- Valoración de Mercancías según Acuerdo del Valor de la OMC. R. I. N. N OOO ADT/ 2000-001545 (p. 06.JUN.2000)

3.3 Normas Supletorias:

a. Texto Único Ordenado del Código Tributario, aprobado por D. S. N ${ }^{\circ} 133$ 2013-EF (Publicado el 22.06.2013)

b. b. Ley del Procedimiento Administrativo General No 27444

c. Ley del Proceso Contencioso Administrativo $\mathrm{N}^{\circ} 27584$

d. Normas de Derecho Común: Código Civil. Código Penal. Derecho Comercial. Derecho Administrativo.

e. Directivas aprobadas por Resoluciones de la SUNAD

f. Circulares que regulan la aplicabilidad de la Ley 